\title{
CAN SMOS SOIL MOISTURE DRY-DOWNS BE USEFUL TO DETECT FLOOD CONDITIONS OVER THE ARGENTINEAN PAMPAS PLAINS?
}

\author{
L. Cappelletti ${ }^{1,}{ }^{*}$, A. Sörensson ${ }^{1}$, R. Ruscica ${ }^{1}$, M. M. Salvia ${ }^{2}$, E. Jobbágy ${ }^{3}$, S. Kuppel ${ }^{4,5}$, L. Fita ${ }^{1}$ \\ ${ }^{1}$ Facultad de Ciencias Exactas y Naturales, Universidad de Buenos Aires (FCEN/UBA). Centro de Investigaciones del Mar y la \\ Atmósfera (CIMA/UBA-CONICET). Institut Franco-Argentin d'Études sur le Climat et ses Impacts (UMI 3351-IFAECI/CNRS-IRD- \\ CONICET-UBA), Intendente Güiraldes 2160, Ciudad Universitaria, C1428EGA, CABA, Argentina - \\ (lucia.cappelletti, sorensson, ruscica, lluis.fita)@cima.fcen.uba.ar \\ ${ }^{2}$ Quantitative Remote Sensing Group, Instituto de Astronomía y Física del Espacio (IAFE, UBA/CONICET), Intendente Güiraldes \\ 2160, Ciudad Universitaria, C1428EGA, CABA, Argentina - msalvia@iafe.uba.ar \\ ${ }^{3}$ Instituto de Matemática Aplicada de San Luis, Av Ejército De Los Andes 950, San Luis (5700), Argentina - jobbagy@unsl.edu.ar \\ ${ }^{4}$ IPGP, CNRS-UMR 7154, Univ. Paris Diderot, USPC, Paris, France \\ ${ }^{5}$ Irstea, UR RiverLy, Centre de Lyon-Villeurbanne, Villeurbanne, France - sylvain.kuppel@irstea.fr
}

KEY WORDS: Soil moisture, floods, SMOS, dry-downs, Pampas Plains

\begin{abstract}
:
The process of soil drying following a single rainfall input offers an integrated perspective on soil-vegetation water dynamics in responses to atmospheric conditions during periods without rainfall. In this work, the soil moisture dry-down time scale events ( $\tau$ ) was calculated using surface soil moisture data from the SMOS mission, with the objective to explore if the spatio-temporal variability of $\tau$ could be used as a proxy for regional flooding and waterlogging characterization. Our working hypothesis is that soil moisture dries up more slowly under flooded conditions as a result of slower surface water elimination by infiltration and capillary rise of water from the saturated zone close to the surface. A clear difference precipitation-moisture coupling was detected between two regions with different flooding dynamics. In a region where flooding is triggered by precipitation excesses on weekly-to-monthly time scales and where the coupling between precipitation and evapotranspiration is strong, a positive correlation between dry-down and 6-month accumulated precipitation anomaly was found for all seasons except winter. By contrast, in the other region where flooding is largely de-coupled from precipitation and evapotranspiration, but rather coupled to ground water table dynamics on time scales from several months to years, no significant correlations were found. These results are based on a short period of data: March 2010 - November 2014.
\end{abstract}

\section{INTRODUCTION}

The Pampas Plains is one of the most productive agricultural regions in South America and is therefore vulnerable to hydrological extremes such as floods and droughts on time scales relevant for agriculture (Lovino et al., 2014, 2018). The interplay between the meteorological extremes and land-use of this region frequently leads to non-harmonic interactions between ecosystem conservation, human well-being and efficient agriculture (Nosetto et al., 2009; Taboada et al., 2009; Viglizzo et al., 2009; Nosetto et al., 2012). The agricultural use of the region also intensifies as a response to international demand and trade (Paruelo et al., 2005). In order to map vulnerability, generate land use policies, determine the spatial extent of emergency situations, and understand causes of hydrological extremes, it is essential to develop analytic tools and indicators describing the dynamics of such hydrological extremes (Ballesteros, 2014).

Soil moisture (SM) is an essential variable in the hydrological cycle and has a direct influence on the development and persistence of floods and droughts (Bonan y Stillwell-Soller, 1998; Entekhabi et al., 1996). In situ measurements are the most accurate method to quantify SM, however, since this variable has a high spatial heterogeneity, each point measurement only represents $1 \mathrm{~m}^{2}$ (Ochsner et al., 2013) and very few measurements are available in the region of study. Thus, remote sensed soil moisture offers a unique alternative to monitor superficial soil moisture (SSM) on the large scale.
The study of SSM dry-downs is an integrative approach for studying SSM dynamics. In this line, the dry-down time scale is determined by the response of the soil to atmospheric conditions, geophysical properties and vegetation type and condition during a period without rainfall (Rondinelli et al., 2015).

The objective of this work is to explore if the spatio-temporal variability of dry-downs can be used as a qualitative indicator of flooding over the Pampas Plains. SSM from the Soil Moisture Ocean Salinity mission (SMOS) is used for the period March 2010 - November 2014.

\section{REGIONAL CHARACTERISTICS}

\subsection{Topography and seasonal precipitation regime}

The region of study is located in the Argentinean Pampas Plains, an extensive plain that covers approximately 600.000 $\mathrm{km}^{2}$, with an altitude of less than 200 meters above sea level (masl) and very small topographic gradients (Figure 1). The flatness of the area leads to slow horizontal movements of water, facilitating the occurrence of flooding (Kruse and Zimmermann, 2002; Viglizzo et al., 2009).

In the south eastern part of the Pampas Plains, several sub regions can be identified according to criteria using topography, geomorphology, presence of drainage systems, dominant vegetation and presence of permanent water bodies. The 
subregions considered for this work (Figure 1) were selected from the work of Kuppel et al. (2015), since they distinguished two different flooding regimes: the Western Pampas (WP) where flooding is coupled to ground water dynamics, and the Lower Pampas (LP) where flooding is more strongly coupled to precipitation and evapotranspiration.

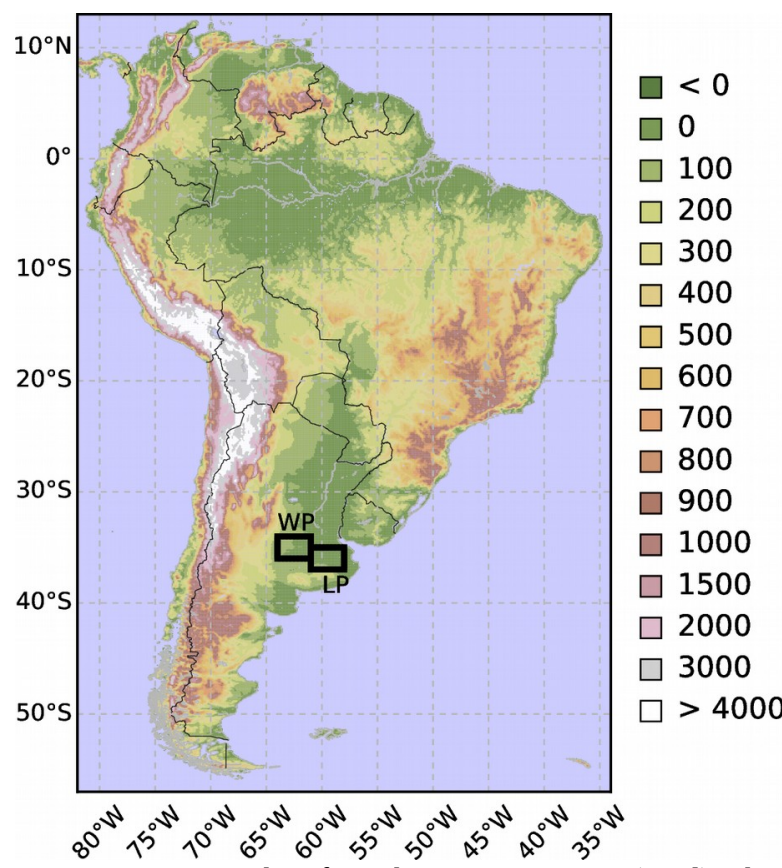

Figure 1. Topography of South America in units (masl). The black rectangles marks the regions of interest for this study.

To characterize the rainfall, precipitation from the Tropical Rainfall Measuring Mission (TRMM) for the period 2000-2014 was employed. The version 3B42 TMPA v7 with spatial resolution of $0.25^{\circ}(\sim 25 \mathrm{~km})$ (Huffman et al., 2010) was used to calculate mean seasonal precipitation (Figure 2). The seasons are labeled as DJF ( $1^{\text {st }}$ of December to $28^{\text {th }}$ of February) for austral summer, MAM ( $1^{\text {st }}$ of March to $31^{\text {st }}$ of May) for austral autumn, JJA ( $1^{\text {st }}$ of June to $31^{\text {st }}$ of August) for austral winter, and SON ( $1^{\text {st }}$ of September to $30^{\text {th }}$ of November) for austral spring. From Figure 2 it is clear that JJA is the driest, while DJF is the wettest season in both WP and LP subregions. LP is wetter than WP during the whole year, with this difference being largest in JJA.

\subsection{Flooding regimes of the Western and Lower Pampas}

Kuppel et al., (2015) studied floods in WP and LP during the period 2000-2013. They estimated the percentage of surface water cover using the large difference in albedo between nonflooded areas (pasture, crops) and water (Loarie et al., 2011, Houspanossian et al., 2018). The albedo product employed was MODIS BRDF/albedo MCD43A (Lucht et al., 2000; Schaaf et al., 2002). To identify the temporal evolution of floods, the monthly mean of surface water (\%) was calculated for each region as well as the monthly time series of 6-month accumulated precipitation anomalies from TRMM 3B42 TMPA v7.

Kuppel et al., (2015) showed that in WP, the flood dynamic presents a slow build-up sequence, and floods can last from several months to years. In this region, soils have a relatively high infiltration capacity and floods are produced by the rise of the water table to the surface after long periods of sustained rainfall. Floods are highly coupled to the ground water level, but not to monthly precipitation and evapotranspiration. On the contrary, in LP, the floods are faster and last weeks to months and are typically generated by the accumulation of surface water on these time scales, or when extreme daily precipitation events exceed the infiltration capacity, which is poorer in this region due to finer soils. The coupling between ground water and floods is low in LP, that is, flooding occurs first, and when the water slowly infiltrates, the ground water is recharged. In LP, evapotranspiration and precipitation are strongly coupled to flooding.
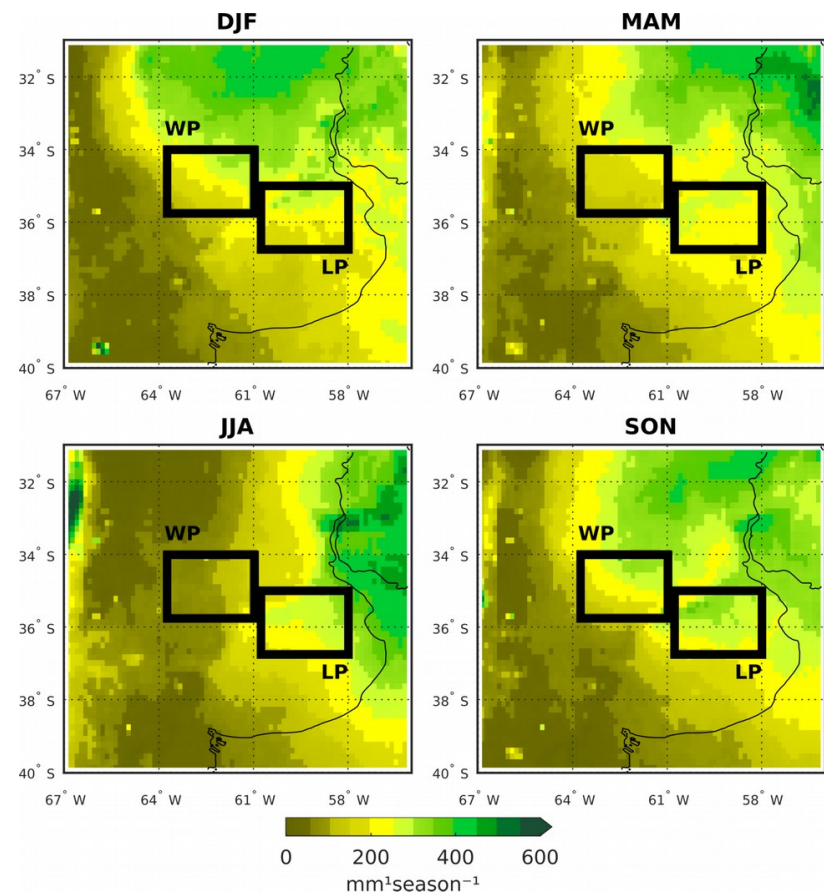

Figure 2. Seasonal mean of TRMM precipitation $\left(\mathrm{mm}^{1}\right.$ season $\left.^{-1}\right)$ for the region of interest during 2000-2014. The subregions Western Pampa (WP) and Lower Pampa (LP) are indicated with black rectangles.

\section{DATA AND METHODOLOGY}

\subsection{SMOS Surface Soil Moisture data}

The SSM used here is from the Soil Moisture Ocean Salinity mission (SMOS, Kerr et al., 2012), launched by the European Space Agency in November 2009. The product version SMOS L3 v.2 was used.

SMOS gives the SSM of approximately the 5 upper centimetres of the surface, using brightness temperature measured in L band by the instrument MIRAS (Microwave Imaging Radiometer Aperture Synthesis, $1.4 \mathrm{GHz}$ ). The product spatial resolution is $25 \mathrm{~km}$. The precision of the measurement (product target accuracy) is $0.04 \mathrm{~m}^{3} \mathrm{~m}^{-3}$.

For this work, only ascending passes (6 AM local time) of SMOS Soil Moisture Level 3 v.2. daily product distributed by the Barcelona Expert Centre were used. This product is obtained through the application of filters and re-gridding of SMOS L2 v.620: the grid points affected by radio frequency interference as well as those measurements that do not satisfy with certain 
quality standards are discarded and the data is interpolated to the 25 km EASE2 grid (Brodzik et al., 2012).

\subsection{The process of soil drying}

In recent studies, the soil drying process has been explored to analyse the spatio-temporal behaviour of the SSM and has also been used to compare Land Surface Models and in situ measurements (McColl et al., 2017; Shellito et al., 2016; Rondinelli et al., 2015). Soil drying is a process which can be quantified by the time it takes to lose water through run off, drainage and evapotranspiration once the entrance of water has taken place through precipitation or, less frequently irrigation (run on) or capillary rise from wetter soils / water table. In Figure 3 the drying process is shown as well as the role of the different mentioned mechanisms of entrance and loss of water content into the soil matrix.

\subsection{Determining drying periods}

First, the drying periods (DPs) are identified in the daily SSM time series for each season during the March 2010 - November 2014 period. Each series refers to a given season and year (e.g., MAM 2012), each of them covering approximately 90 days. Note that, due to the revisit time of SMOS, not all days have data. The methodology used to identify the DPs for each grid point of the area under study is described below:

i. A DP starts when a SSM estimated by SMOS increases at least $0.1 \mathrm{~m}^{3} \mathrm{~m}^{-3}$. From one available SSM data to the next.

ii. The DP lasts as long as day-to-day SSM variations are negative or within the product target accuracy (0.04 $\left.\mathrm{m}^{3} \mathrm{~m}^{-3}\right)$.

iii. Only DPs of at least 5 days and with at least 4 estimates of SSM are considered.

\subsection{Estimation of the dry-down time scale ( $\tau$ )}

To determine each dry-down time scale $\tau$ of the DPs identified in the previous step, the SSM values of each DP time series were fitted to an exponential function (McColl et al., 2017; Shellito et al., 2016; Rondinelli et al., 2015) of the form:

$$
\operatorname{SSM}(t)=A * \exp (-t / \tau)+S_{S M}
$$

where $\quad A=$ amplitude of the dry-down $\left(\mathrm{m}^{3} / \mathrm{m}^{3}\right)$

$\mathrm{t}=$ time since the beginning of the dry-down (days)

$\tau=$ dry-down time scale (days) and

$\mathrm{SSM}_{\mathrm{f}}=\mathrm{SSM}$ equilibrium value $\left(\mathrm{m}^{3} / \mathrm{m}^{3}\right)$

In this work, the dry-down time $(\tau)$ scale is used as an indicator of top soil drying velocity, although its unit is given in days. Large $\tau$ values refer to slow soil drying and small $\tau$ values refer to fast drying. For each identified DP a minimum square fitting of the A, $\mathrm{SSM}_{\mathrm{f}}$ and $\mathrm{t}$ of the equation (1) was done. In order to avoid spurious data, the fitted parameters were restricted by the following way: SSM $_{\mathrm{f}}$ parameter, has to be lower than the minimum soil humidity measured during the DP event and larger or equal than the lowest SSM observed during the entire period of time (March 2010 - November 2014). t cannot be longer than the length of a season (90 days). Additionally, only the $\tau$ values from SMOS DPs with determination coefficients of the exponential adjustment larger than $0.7 \quad\left(\mathrm{R}^{2}>0.7\right)$ are considered.

\subsection{Can $\mathrm{x}$ be useful to determine flood occurrence?}

As was previously mentioned, the study of Kuppel et al., (2015) reports and characterizes the flooding events that occur in the WP and LP regions using monthly time series of 6-month accumulated precipitation anomalies. They found that flood occurrence is connected to accumulated precipitation anomalies on this timescale in both regions. However, on the annual time scale, flood occurrence in LP is coupled to precipitation, but in WP is rather coupled to the water table. Here, it is explored if the simultaneous use of the temporal variability of $\tau$ from SMOS and the 6-month accumulated precipitation anomalies can be useful to determine flood events in the two regions. As a first step in determining if $\tau$ could be a useful indicator of flooding, the correlation between the monthly time series of $\tau$ and the monthly 6-month accumulated precipitation anomalies was calculated.

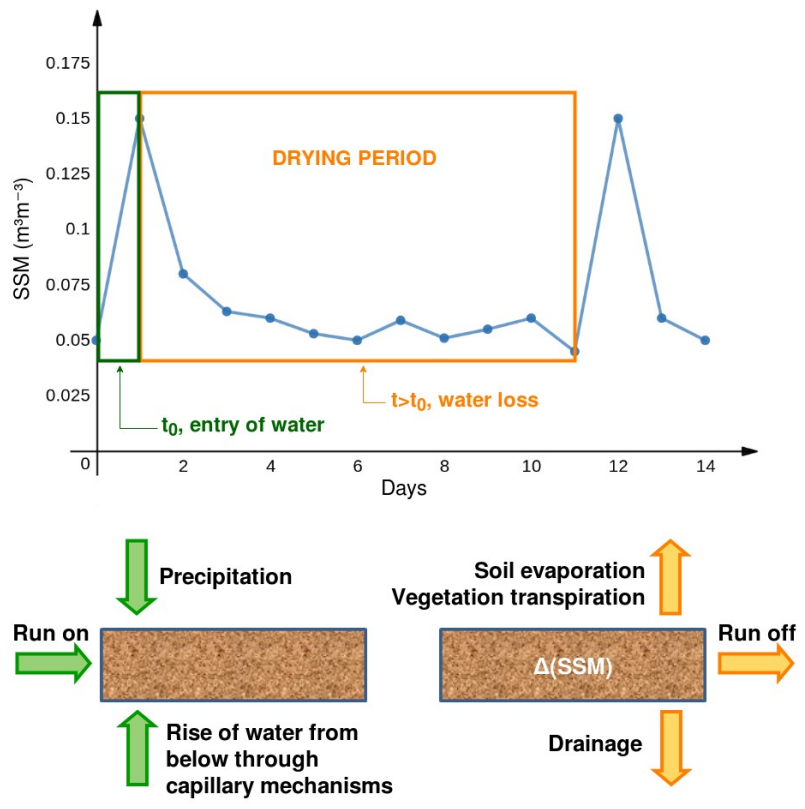

Figure 3. Illustration of the drying process of the soil: The drying period starts when there is an input of water (green arrows) which increases SSM, either by precipitation or run on, or more gradually, by capillary flow if water tables rise close enough to the surface. Drying (orange arrows) results from evapotranspiration, run off and drainage, modifying the SSM $(\Delta \mathrm{SSM})$.

\section{RESULTS AND DISCUSSION}

Seasonal medians of the $\tau$ value at each grid point and season were computed. Seasonal spatial patterns are shown in Figure 4. The figure shows a large spatial variability of the $\tau$ value over the region, with median values ranging from 2 to 20 days. The pattern of spatial variability also presents seasonal differences, that is, the process of soil drying depends both on the region and the season. In general, the median values of $\tau$ over the area of interest follow an annual cycle with the largest values corresponding with the austral winter (JJA), lowest values for summer (DJF) and intermediate values for the other seasons. Autumn (MAM) depicts values slightly higher than austral spring (SON). For JJA many grid points lack data, that is, either no DP was identified, or the SSM values of an identified period could not be fitted to the exponential function complying with 
the criteria described above. This lack of data limits the analysis of this season.
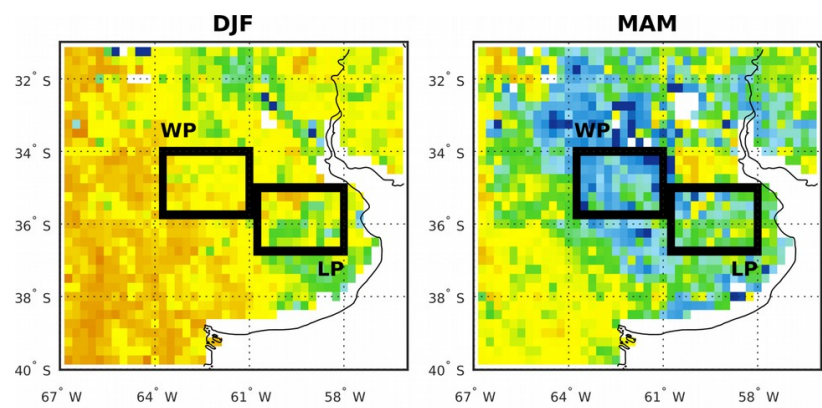

JJA

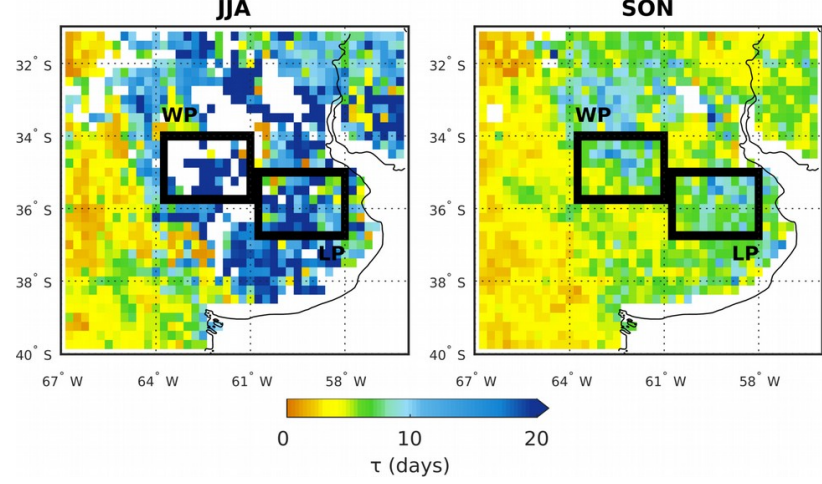

Figure 4. Surface soil drying metric: Maps of seasonal median of $\tau$ (days) computed at each grid point. White colour corresponds to lack of DP or that the SSM values of the DPs identified could not be fitted to the exponential to determine $\tau$.

WP and LP regions are marked with black rectangles.

As can be seen in Figure 4, the drying process has a strong seasonality. For this reason, the correlations between monthly $\mathrm{\tau}$ and monthly 6-month accumulated precipitation anomaly are calculated for each season separately. The following method was applied: (1) for each region (WP, LP) 15 monthly values are available for MAM, JJA and SON, while for DJF 12 values are available. Each median value matches in time with one 6-month accumulated anomaly of TRMM. With the data ordered in this way, (2) the Pearson correlation coefficient was computed between the monthly median of $\tau$ ordered by season and the anomaly of precipitation for the March 2010 - November 2014 period. Obtained values are shown in Table 1 , where only the LP region has significant values for $p<0.15$ for all the seasons except JJA.

\begin{tabular}{|c|c|c|}
\hline & WP & LP \\
\hline DJF & 0.29 & $\mathbf{0 . 4 5}$ \\
\hline MAM & 0.14 & $\mathbf{0 . 4 0}$ \\
\hline JJA & 0.05 & 0.03 \\
\hline SON & 0.06 & $\mathbf{0 . 4 0}$ \\
\hline
\end{tabular}

Table 1. Pearson correlation coefficient (r) between the monthly median of $\mathrm{\tau}$ classified by season and the accumulated

precipitation anomaly for the March 2010 - November 2014 period for the WP and LP regions. Significant values at $p<0.15$ level of confidence are marked in bold.
Figure 4 and Table 1 show that the behaviour of SMOS satellite derived $\mathrm{\tau}$ could be consistent with the study of Kuppel et al. (2015). The WP region floods are slow and not directly coupled to precipitation but rather to water table levels which have a slower dynamics. Over WP the infiltration rates are sufficiently fast to drain and raise water tables before floods occur. Once at the surface, water tables produce long lasting floods, which sustained by positive precipitation anomalies can last for several years. By contrast, in the LP region, the connectivity between ground and surface water is weaker. Flood episodes are triggered by precipitation anomalies on time scales of weeks to months. Moreover, Kuppel et al., (2015) showed that in this region, precipitation and evapotranspiration are strongly coupled and at the same time are the key ingredients that determine the drying period of the soil.

Although this is a preliminary version of the study, since there are only 12-15 values to calculate the correlation, the results displayed in Table 1 are coherent with this characterization of the two subregions. In LP, $\mathrm{r}$ is significant $(p<0.15)$ except in $\mathrm{JJA}$ for which there is very few $\tau$ values (Figure 4 , JJA) and the $\tau$ are very large due to limited radiation input during winter. On the other hand, in WP, $\mathrm{r}$ is not significant for any season, which is in line with the fact that flood occurrence in WP is not as coupled to precipitation as in LP.

Finally, periods of missing data were identified as a key factor hindering the analysis of the variability of the soil drying period as a quantitative index of floods and waterlogging. Low correlation and non-significance for JJA might be related to the small amount of data of monthly $\tau$ during that part of the year.

\section{CONCLUSIONS}

It was possible to determine a significant correlation between SMOS derived monthly $\tau$, and the monthly 6-month accumulated precipitation anomalies over the LP region. This region is characterized by recurrent fast floods triggered by positive, short and intense rainfall events and precipitationevapotranspiration coupling is strong. This is not the case for the WP region, where water tables propitiate a slower dynamics. Deeper analysis of the physical processes related to the drying of the soil as well as analyses over longer periods are necessary to determine the utility of $\mathrm{\tau}$ as signature of flood dynamics.

\section{ACKNOWLEDGEMENTS}

This work was supported by the Agencia Nacional de Promoción Científica y Tecnológica (ANPCyT) projects PICT 2017-1406 and 2015-3097 and the International Inter-American Institute for Global Change Research (IAI) CRN 3035, which is supported by the U.S. National Science Foundation under Grant [GEO-1128040]. SMOS SM data are freely available at BEC website: http://cp34-bec.cmima.csic.es/.

\section{REFERENCES}

Ballesteros, S., 2014: Inundaciones y su relación con el clima y la hidrología subterránea en el Noroeste de Buenos Aires (19802010): Aplicación de percepción remota. Master's thesis, Facultad de Agronomía, Universidad de Buenos Aires, Argentina. 
Bonan, G.B., Stillwell-Soller, L.M., 1998: Soil water and the persistence of floods and droughts in the Mississippi River Basin. Water Resources Research, 34(10):2693-2701.

Brodzik, M.J., Billingsley, B., Haran, T., Raup, B., Savoie, M.H., 2012: EASE-Grid 2.0: Incremental but significant improvements for Earth-Gridded Data Sets. ISPRS International Journal of GeoInformation, 1(1):32-45.

Entekhabi, D., Rodriguez-Iturbe, I., Castelli, F., 1996: Mutual interaction of soil moisture state and atmospheric processes. Journal of Hydrology, 184(1-2):3-17.

Gumuzzio, A., Brocca, L., Sánchez, N., González-Zamora, A., Martínez-Fernández, J., 2016: Comparison of SMOS, modelled and in situ long-term soil moisture series in the northwest of Spain. Hydrological Sciences Journal, 61(14):2610-2625.

Houspanossian, J., et al., 2018: Long-lasting floods buffer the thermal regime of the Pampas. Theoretical and applied climatology, 131.1-2: 111-120.

Huffman, G.J., Adler, R.F., Bolvin, D.T., Nelkin, E.J., 2010: The TRMM Multi-Satellite Precipitation Analysis (TMPA), pages 3 22. Springer Netherlands, Dordrecht.

Kerr, Y.H., Waldteufel, P., Richaume, P., Wigneron, J.P., Ferrazzoli, P., et al., 2012: The SMOS soil moisture retrieval algorithm. IEEE Transactions on Geoscience and Remote Sensing, 50(5):1384-1403.

Kruse, E., Zimmermann, E., 2002: Hidrogeología de grandes llanuras. particularidades en la llanura pampeana (Argentina). Workshop Publication on Groundwater and Human Development, pages 2025-2038.

Kuppel, S., Houspanossian, J., Nosetto, M.D., Jobbágy, E.G., 2015: What does it take to flood the Pampas?: Lessons from a decade of strong hydrological fluctuations. Water Resources Research, 51(4):2937-2950.

Lacava, T., Matgen, P., Brocca, L., Bittelli, M., Pergola, N., Moramarco, T., Tramutoli, V., 2012: A First Assessment of the SMOS Soil Moisture Product With In Situ and Modeled Data in Italy and Luxembourg. IEEE Transactions on Geoscience and Remote Sensing, 50(5):1612-1622.

Loarie, S.R., Lobell, D.B., Asner, G.P., Field, C.B., 2011: Landcover and surface water change drive large albedo increases in South America. Earth Interactions, 15(7):1-16.

Lovino, M., García, N.O., Baethgen, W., 2014: Spatiotemporal analysis of extreme precipitation events in the Northeast region of Argentina (NEA). Journal of Hydrology: Regional Studies, 2:140-158.

Lovino, M., Müller, O.V., Müller, G.V., Sgroi, L.C., Baethgen, W.E., 2018: Interannual-to-multidecadal hydroclimate variability and its sectoral impacts in northeastern Argentina. Hydrology and Earth System Sciences, 22(6):3155-3174.

Leroux, D.J., Kerr, Y.H., Al Bitar, A., Bindlish, R., Jackson, T.J., Berthelot, B., Portet, G., 2014: Comparison between SMOS, vua, ascat, and ecmwf soil moisture products over four watersheds in US. IEEE Transactions on Geoscience and Remote Sensing, 52(3):1562-1571.

Lucht, W., Schaaf, C.B., Strahler, A.H., 2000: An algorithm for the retrieval of albedo from space using semiempirical BRDF models. IEEE Transactions on Geoscience and Remote Sensing, 38(2): 977-998.

McColl, K.A., Wang, W., Peng, B., Akbar, R., Short Gianotti, D.J., Lu, H., Pan, M., Entekhabi, D., 2017: Global characterization of surface soil moisture drydowns. Geophysical Research Letters, 44(8):3682-3690.

Nosetto, M.D., Jobbágy, E.G., Jackson, R., Sznaider, G., 2009: Reciprocal influence of crops and shallow ground water in sandy landscapes of the Inland Pampas. Field Crops Research, 113(2):138- 148

Nosetto, M.D., Jobbágy, E.G., Brizuela, A.B., Jackson, R., 2012: The hydrologic consequences of land cover change in central Argentina. Agriculture, Ecosystems \& Environment, 154:2-11.

Ochsner, T.E., Cosh, M.H., Cuenca, R.H., Dorigo, W.A., Draper, C.S., Hagimoto, Y., et al., 2013: State of the Art in Large-Scale Soil Moisture Monitoring. Soil Sci. Soc. Am. J. 77, 1888. doi:10.2136/sssaj2013.03.0093.

Paruelo, J., Guerschman, J., Verón, S., 2005:. Expansión agrícola y cambios en el uso del suelo. Ciencia Hoy, 15:14-23.

Rondinelli, W.J., Hornbuckle, B.K., Patton, J.C., Cosh, M.H., Walker, V.A., Carr, B.D., Logsdon, S.D., 2015: Different Rates of Soil Drying after Rainfall Are Observed by the SMOS Satellite and the South Fork in situ Soil Moisture Network. Journal of Hydrometeorology, 16(2):889-903.

Schaaf, C.B., Gao, F., Strahler, A.H., Lucht, W., Li, X., Tsang, T., Strugnell, N.C., Zhang, X., Jin, Y., Muller, J.P., et al., 2002: First operational BRDF, albedo nadir reflectance products from MODIS. Remote sensing of Environment, 83(1-2):135-148.

Shellito, P.J., Small, E.E., Colliander, A., Bindlish, R., Cosh, M.H., Berg, A.A., Bosch, D.D., Caldwell, T.G., Goodrich, D.C., McNairn, H., Prueger, J.H., Starks, P.J., van der Velde, R., Walker, J.P., 2016: SMAP soil moisture drying more rapid than observed in situ following rainfall events. Geophysical Research Letters, 43(15):8068-8075.

Taboada, M., Damiano, F., Lavado, R., 2009: Inundaciones en la Región Pampeana. Consecuencias sobre los suelos, pages 103-127. Universidad de Buenos Aires, Buenos Aires, Argentina.

Viglizzo, E.F., Jobbágy, E.G., Carreño, L., Frank, F.C., Aragón, R., De Oro, L., Salvador, V., 2009: The dynamics of cultivation and floods in arable lands of Central Argentina. Hydrology and Earth System Sciences, 13(4):491-502. 